\title{
Erratum
}

\section{The theory of justice}

\section{Serge-Christophe Kolm}

Paris, France

In: Soc Choice Welfare (1996) 13:151-182

On page 157 of the above paper the third column in Table 1 was misprinted. The table should read as follows:

Table 1. The allocation of human resources

\begin{tabular}{|c|c|c|c|c|}
\hline \multirow{2}{*}{ Capacities } & \multicolumn{2}{|c|}{ Consumptive Natural } & \multirow{2}{*}{$\frac{\text { Natural }}{\text { Equalize }}$} & \multirow{2}{*}{$\frac{\text { Equalize }}{\text { Equalize }}$} \\
\hline & Productive & Natural & & \\
\hline Equalizand & & Process-freedom & Income, consumption & Satisfaction \\
\hline Name & & $\begin{array}{l}\text { Full Process- } \\
\text { Liberalism }\end{array}$ & $\begin{array}{l}\text { Equal consumption } \\
\text { or income }\end{array}$ & $\begin{array}{l}\text { (Needs or ends) } \\
\text { full Justice }\end{array}$ \\
\hline For efficiency & & $\begin{array}{l}\text { Liberal Social Contract } \\
\text { (public sector, } \\
\text { Kolm 1985) }\end{array}$ & $\begin{array}{l}\text { Efficient Super-Equity } \\
\text { (multidimensional } \\
\text { maximin, Kolm 1973, } \\
\text { 91-94) } \\
\text { Fixed-duration } \\
\text { Income Equalization } \\
\text { (Kolm 1991 -93-94) }\end{array}$ & $\begin{array}{l}\text { Basic needs or } \\
\text { Practical Justice } \\
\text { (leximin in } \\
\text { fundamental } \\
\text { satisfaction, } \\
\text { Kolm 1971) }\end{array}$ \\
\hline $\begin{array}{l}\text { Irrational } \\
\text { formulations }\end{array}$ & & $\begin{array}{l}\text { Private Full Process- } \\
\text { Liberalism } \\
\text { (Locke 1689, } \\
\text { 1789, classical } \\
\text { "Political Economy", } \\
\text { Nozick 1974) }\end{array}$ & $\begin{array}{l}\text { Equalizand as: } \\
\text { (1) Consumption goods } \\
\text { (Tobin 1970) } \\
\text { (2) Spheres of Justice } \\
\text { (Weber, Walzer 1983) } \\
\text { (3) Primary goods } \\
\text { (Rawls 1971) } \\
\text { (4) Resources } \\
\text { (Dworkin 1981) }\end{array}$ & $\begin{array}{l}\text { Utilitarianism, } \\
\text { "Social Welfare" }\end{array}$ \\
\hline $\begin{array}{l}\text { Error-inducing } \\
\text { omission }\end{array}$ & & Market failures & $\begin{array}{l}\text { Either inefficiency of } \\
\text { multidimensional } \\
\text { equality }(1,2) \text {, or } \\
\text { exchange capacities } \\
(2,3,4) \text {, or the ethical } \\
\text { value of prices }(2,3) \text {. }\end{array}$ & $\begin{array}{l}\text { The rationality } \\
\text { of equality }\end{array}$ \\
\hline
\end{tabular}

